\title{
Reirradiation spine stereotactic body radiation therapy for spinal metastases: systematic review
}

\author{
International Stereotactic Radiosurgery Society practice guidelines
}

\author{
Sten Myrehaug, MD, ${ }^{1}$ Arjun Sahgal, MD, ${ }^{1}$ Motohiro Hayashi, MD, ${ }^{2}$ Marc Levivier, MD, ${ }^{3}$ \\ Lijun Ma, PhD, ${ }^{4}$ Roberto Martinez, MD, ${ }^{5}$ lan Paddick, MSc, ${ }^{6}$ Jean Régis, MD, ${ }^{7}$ Samuel Ryu, MD, ${ }^{8}$ \\ Ben Slotman, MD, PhD, ${ }^{9}$ and Antonio De Salles, MD, PhD ${ }^{10}$
}

\begin{abstract}
'Department of Radiation Oncology, University of Toronto, Sunnybrook Odette Cancer Centre, Toronto, Ontario, Canada; 2Department of Neurosurgery, Tokyo Women's Medical University, Tokyo, Japan; ${ }^{3}$ Neurosurgery Service and Gamma Knife Center, Centre Hospitalier Universitaire Vaudois, Lausanne, Switzerland; ${ }^{4}$ Division of Physics, Department of Radiation Oncology, University of California, San Francisco, California; ${ }^{5}$ Department Neurosurgery, Ruber Internacional Hospital, Madrid, Spain; ${ }^{6}$ National Hospital for Neurology \& Neurosurgery, University College London, United Kingdom; ${ }^{7}$ Department of Functional Neurosurgery, Timone University Hospital, Aix-Marseille University, Marseille, France; ${ }^{8}$ Department of Radiation Oncology and Neurosurgery, Stony Brook University, Stony Brook, New York; ${ }^{2}$ Department of Radiation Oncology, VU University Medical Center, Amsterdam, The Netherlands; and ${ }^{10}$ Department of Neurosurgery, University of California, Los Angeles, California, and HCor Neuroscience, São Paulo, Brazil
\end{abstract}

OBJECTIVE Spinal metastases that recur after conventional palliative radiotherapy have historically been difficult to manage due to concerns of spinal cord toxicity in the retreatment setting. Spine stereotactic body radiation therapy (SBRT), also known as stereotactic radiosurgery, is emerging as an effective and safe means of delivering ablative doses to these recurrent tumors. The authors performed a systematic review of the literature to determine the clinical efficacy and safety of spine SBRT specific to previously irradiated spinal metastases.

METHODS A systematic literature review was conducted, which was specific to SBRT to the spine, using MEDLINE, Embase, Cochrane Evidence-Based Medicine Database, National Guideline Clearinghouse, and CMA Infobase, with further bibliographic review of appropriate articles. Research questions included: 1) Is retreatment spine SBRT efficacious with respect to local control and symptom control? 2) Is retreatment spine SBRT safe?

RESULTS The initial literature search retrieved 2263 articles. Of these articles, 160 were potentially relevant, 105 were selected for in-depth review, and 9 studies met all inclusion criteria for analysis. All studies were single-institution series, including 4 retrospective, 3 retrospective series of prospective databases, 1 prospective, and 1 Phase I/II prospective study (low- or very low-quality data). The results indicated that spine SBRT is effective, with a median 1-year local control rate of $76 \%$ (range $66 \%-90 \%$ ). Improvement in patients' pain scores post-SBRT ranged from $65 \%$ to $81 \%$. Treatment delivery was safe, with crude rates of vertebral body fracture of $12 \%$ (range $0 \%-22 \%$ ) and radiation-induced myelopathy of $1.2 \%$.

CONCLUSIONS This systematic literature review suggests that SBRT to previously irradiated spinal metastases is safe and effective with respect to both local control and pain relief. Although the evidence is limited to low-quality data, SBRT can be a recommended treatment option for reirradiation.

https://thejns.org/doi/abs/10.3171/2017.2.SPINE16976

KEY WORDS spine; vertebral body; metastases; retreatment; stereotactic radiation; oncology

ABBREVIATIONS BPI = Brief Pain Inventory; cEBRT = conventional palliative fractionated external-beam radiotherapy; CR = complete response; ISRS = International Stereotactic Radiosurgery Society; SBRT = stereotactic body radiotherapy; VCF = vertebral compression fracture.

SUBMITTED August 20, 2016. ACCEPTED February 6, 2017.

INCLUDE WHEN CITING Published online July 14, 2017; DOI: 10.3171/2017.2.SPINE16976. 
$\mathrm{S}$ PINAL metastases may cause significant symptoms, ranging from pain to potentially catastrophic neurological compromise. In cases where surgical management is not indicated, conventional palliative fractionated external-beam radiotherapy (cEBRT) has been a standard of care management option. The efficacy of cEBRT has been limited to complete response (CR) rates of $0 \%-20 \%$ and partial response rates of approximately $60 \% .^{5}$ Approximately $20 \%$ of patients treated with lowdose cEBRT (e.g., 8 Gy in 1 fraction) will require reirradiation due to pain progression within months of the first treatment course. The need for reirradiation is expected only to increase as more effective surgical, radiation, and systemic therapies continue to result in longer lengths of patient survival.

Management of progressive spinal disease within a previously irradiated volume has been a major challenge given the proximity of several critical structures, in particular, the spinal cord. Respecting the cumulative tolerance of the spinal cord has historically led to conservative practice among radiation oncologists and retreatment with lower biologically effective doses than initially delivered. ${ }^{6,16}$ This probably explains the disappointing results following reirradiation cEBRT, with a meta-analysis reporting overall response rates of approximately 58\% and CR rates ranging from $16 \%$ to $28 \% .^{12}$

A recent Phase III randomized trial compared reirradiation cEBRT (8 Gy in a single fraction vs 20 Gy in 5 fractions) for painful, previously irradiated bone metastases, of which $28 \%$ were spine metastases. Response to therapy with either fractionation scheme was modest at best, with overall response rates of $45 \%$ and $51 \%$, respectively, and CR rates of only $14 \%$ and $11 \%$, respectively. ${ }^{6}$ This suggests that there is a critical need to improve outcomes in these patients.

With the advent of modern radiation planning and image-guided radiotherapy apparatuses, the ability to deliver stereotactic ablative radiation to body targets gave rise to stereotactic body radiotherapy (SBRT), which is also known as spine stereotactic radiosurgery. In fact, the field started with reirradiation as the primary application, and in 1995 Hamilton et al. ${ }^{11}$ reported the first spine SBRT series (5 patients) based on a rigid spinal immobilization device and delivery of 10 Gy in a single fraction. MilkerZabel et al. ${ }^{15}$ further reported on the use of a noninvasive near-rigid external body immobilization and conformal treatment delivery.

Now, with more than a decade of clinical experience, multiple studies have been reported, although they are limited largely to single-institution series. The intent of this systematic literature review was to summarize the literature, determine efficacy and safety of reirradiation SBRT, and provide treatment recommendations on behalf of the International Stereotactic Radiosurgery Society (ISRS).

\section{Methods}

A systematic review of the literature was performed according to the Preferred Reporting Items for Systematic Reviews and Meta-Analyses guidelines (Fig. 1). The search was limited to data published between January 2005 and May 2015 (to limit data to modern immobilization, planning, and image-verification techniques). Articles were selected for clinical relevance to the following research questions: 1) Is retreatment spine SBRT efficacious with respect to local control and symptom control? 2) Is retreatment spine SBRT safe?

Exclusion criteria included surgical series without reirradiation data, treatment of primary spine/CNS disease, non-peer-reviewed manuscripts, reviews without original data, nonclinical outcomes (radiation planning/physics studies or imaging studies), and case series $<10$ patients.

The Embase, MEDLINE, Cochrane, CMA Infobase, and National Guidelines Clearinghouse databases were searched (Table 1). A total of 2263 citations were identified (MEDLINE, $\mathrm{n}=699$; Embase, $\mathrm{n}=1499$; CMA Infobase, $\mathrm{n}=1$; Cochrane Evidence-Based Medicine Database, $\mathrm{n}=14$; and National Guidelines Clearinghouse, $\mathrm{n}$ $=23)$. After eliminating duplicate citations $(\mathrm{n}=258)$ and applying initial exclusion criteria, 160 potentially relevant abstracts were selected for in-depth review by independent duplicate-data extraction.

The refined exclusion criteria included the following parameters: must define and report local control specific to reirradiation SBRT, treatment of metastatic disease alone or, if combined with primary tumors, then data for reirradiation SBRT segregated such that outcomes could be determined, use of hypofractionation doses (> $5 \mathrm{~Gy} /$ fraction), and use of modern planning (fusion of CT simulation data set with MRI or CT myelogram, inverse planning, robust immobilization, and online imaging). Seven studies met all inclusion criteria; an additional 2 studies were selected based on unpublished supplementary information provided by the corresponding author. Levels of evidence for recommendations are described in Table 2. Grading of Recommendations Assessment, Development and Evaluation criteria were used to critically evaluate the quality of each data set, as reported in Table 3.

\section{Data Summary}

Following the review of 2263 articles, 160 were selected for detailed review, of which 9 met inclusion criteria. One manuscript that reported on 2 Phase I/II trials was identified, ${ }^{9}$ as were 4 retrospective series, $, 3,7,14,173$ retrospective series of prospective databases, ${ }^{4,21,22}$ and 1 prospective report. ${ }^{1}$ Two publications were from 1 institution, which may have introduced an element of bias when providing generalizable results. The number of spinal segments treated in each publication ranged from 11 to 97 segments.

Reported experiences were heterogeneous with regard to patient, tumor, and treatment characteristics such as histology, presence of epidural disease, prior treatments (resection, median initial radiation dose), radiation delivery technique, and follow-up approach (imaging type, frequency of imaging, clinical examination). Reported retreatment regimens ranged from single-fraction SBRT to multiple-fraction SBRT (2-5 fractions), and median total doses ranged from 20 to $30 \mathrm{~Gy}$. Dose to the critical neural structures (spinal cord, thecal sac) also ranged widely across studies, dependent on fractionation scheme used for retreatment and prior radiation dose received. Selected 


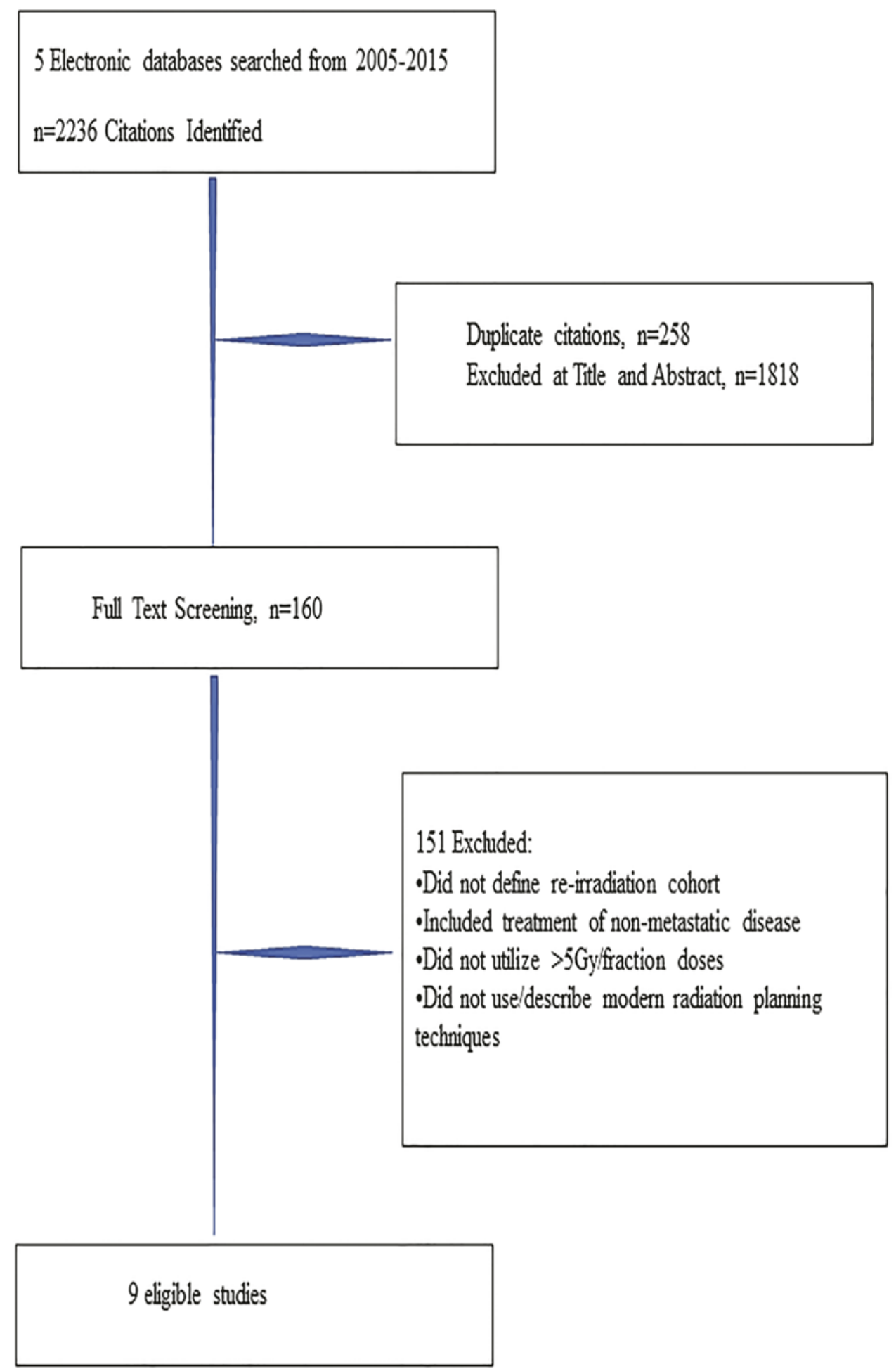

FIG. 1. Preferred Reporting Items for Systematic Reviews and Meta-Analyses diagram. Figure is available in color online only.

treatment details are reported in Table 3, and clinical outcomes are listed in Table 4.

\section{Results}

\section{Patient Selection}

Study patient populations were heterogeneous; how- ever, some similarities in selection criteria were observed. With regard to clinical presentation, no study allowed patients with acute malignant epidural spinal cord compression. Three of 9 studies allowed surgical stabilization prior to SBRT delivery, and 65\% of patients studied (range $8 \%-100 \%$ ) had tumors classically recognized as radioresistant including sarcoma, renal cell carcinoma, non- 
TABLE 1. Database search terms

\begin{tabular}{|c|c|}
\hline No. & Search Term \\
\hline 1 & exp Spinal Neoplasms \\
\hline 2 & exp Spinal Cord Neoplasms \\
\hline 3 & 1 or 2 \\
\hline 4 & exp Radiosurgery \\
\hline 5 & exp Radiotherapy \\
\hline 6 & $\begin{array}{l}\text { (stereotactic adj5 (radiotherapy or radiosurgery or } \\
\text { radiation or irradiation)).mp. }\end{array}$ \\
\hline 7 & sbrt.mp. \\
\hline 8 & sabr.mp. \\
\hline 9 & or/4-8 \\
\hline 10 & 3 and 9 \\
\hline 11 & limit 10 to (editorial or letter or news) \\
\hline 12 & 10 not 11 \\
\hline 13 & limit 12 to (English language and humans) \\
\hline 14 & limit 13 to $y r=" 2005$-Current" \\
\hline 15 & Retreatment \\
\hline 16 & retreatment.mp. \\
\hline 17 & reirradiation.mp. \\
\hline 18 & 15 or 16 or 17 \\
\hline 19 & 14 and 18 \\
\hline 20 & 14 not 19 \\
\hline
\end{tabular}

small cell lung carcinoma, melanoma, and gastrointestinal tract tumors. ${ }^{10}$

\section{Local Control and Overall Survival With Reirradiation SBRT Following cEBRT}

Outcomes from 3 nonrandomized prospective case series, 1 Phase I/II prospective study, and 4 retrospective series (411 treated spinal segments in total) were identified for analyses. Definition of local failure varied from radiographic in-field progression to radiographic and/or clinical progression. Follow-up protocols varied from posttreatment CT scan, standard MRI follow-up, to undefined. The median overall survival ranged from 10 to 22.5 months. The median follow-up was 12.1 months (range 7-17.6 months). The median local control at 1 year was $76 \%$ (range 66\%-90\%). With regard to pattern of failure, epidural disease was the most common site of progression, as reported by Choi et al. ${ }^{4}(38 \%)$ and Thibault et al. ${ }^{21}(63 \%)$. Similarly, 2 other studies identified higher rates of failure in patients with disease close to the spinal cord. 3,9

\section{Local Control and Overall Survival With Reirradiation SBRT Following SBRT}

One article uniquely reported on patients treated with SBRT to salvage post-SBRT failures. Local control was defined as radiographic progression on MRI. With a median follow-up of 6.8 months, the median overall survival was 10.0 months. The 1-year local control rate was $81 \%$. The epidural space was the most common site of disease progression $(85 \%)$. Despite this aggressive radia-
TABLE 2. Levels of evidence

\begin{tabular}{cc}
\hline Evidence Level & Description \\
\hline $\begin{array}{c}\text { Level I } \\
\text { evidence }\end{array}$ & $\begin{array}{c}\text { Evidence from well-designed, randomized controlled } \\
\text { clinical trials, including meta-analyses }\end{array}$ \\
\hline $\begin{array}{c}\text { Level II } \\
\text { evidence }\end{array}$ & $\begin{array}{c}\text { Evidence from comparative clinical studies (non- } \\
\text { randomized cohort studies, case-control studies, } \\
\text { less well-designed randomized controlled trials) }\end{array}$ \\
\hline $\begin{array}{c}\text { Level III } \\
\text { evidence }\end{array}$ & $\begin{array}{c}\text { Low-quality evidence from case series, comparative } \\
\text { studies w/ historical controls, case reports, expert } \\
\text { opinion, \& flawed randomized controlled trials }\end{array}$ \\
\hline
\end{tabular}

tion course, no vertebral compression fractures (VCFs) or Grade III toxicity were observed.

\section{Pain Control}

Heterogeneity was observed with respect to reporting pain outcomes, and in the 5 series that did report on pain, the assessment tools were not consistent. In this review, a crude assessment based on both subjective and objective measurement suggests that pain control following SBRT was observed in 65\%-81\% of cases. Four studies presented outcomes based on subjective physician/patient reports, ${ }^{3,4,7,14}$ and 1 study ${ }^{9}$ formally assessed pain using the validated Brief Pain Inventory (BPI). Based on the prospectively reported BPI, significantly improved pain control is seen at 1,3 , and 6 months after retreatment with SBRT. ${ }^{9}$ Further details of pain control in this patient group pooled with patients without prior radiotherapy were reported in 2012. ${ }^{25}$

\section{Adverse Events Following Reirradiation Spine SBRT}

Based on the 9 articles, Table 5 summarizes reported adverse events. Only 3 articles specifically reported VCF as an adverse event, and of the 186 spinal segments, 22 developed VCF (12\%). The highest risk of fracture was observed in patients treated with single-fraction therapy (12 of 54). With respect to radiation-induced myelopathy, of the 411 spinal segments treated, 8 cases of symptomatic myelopathy were observed (crude risk 1.2\%). No other Grade III-IV toxicities were reported.

\section{ISRS Recommendations}

ISRS recommendations are listed in Table 6. Given the complex clinical nature of patients with progressive painful metastases following radiation, multidisciplinary assessment is essential to patient management. In particular, for patients with high-grade epidural disease or instability, a surgical consultation should be obtained prior to radiation. In those patients deemed appropriate for reirradiation, the evidence suggests spine SBRT as a recommended treatment strategy following either conventionally delivered radiotherapy or to salvage SBRT failures, with the intent to optimize local control and pain control. No specific SBRT regimen has been proven superior to another, and the optimal dose and fractionation remain an area of active investigation. Paramount to any SBRT plan is careful delineation of the critical neural structures and strict adherence to safe dose limits. Reirradiation spinal cord 
TABLE 3. Details of radiation delivery for reviewed articles

\begin{tabular}{|c|c|c|c|c|c|c|}
\hline Authors \& Year & Study Type & $\begin{array}{l}\text { Targets Treated/ } \\
\text { Total No. of Patients }\end{array}$ & $\begin{array}{l}\text { Median Initial RT } \\
\text { Dose }\end{array}$ & $\begin{array}{l}\text { Retreatment } \\
\text { Modality }\end{array}$ & Retreatment Dose & $\begin{array}{c}\text { Study Quality } \\
\text { (GRADE) }\end{array}$ \\
\hline Sahgal et al., 2009 & Retrospective & $37 / 25$ & $36 \mathrm{~Gy} / 14 \mathrm{frx}$ & CyberKnife & $24 \mathrm{~Gy} / 3$ frx to $60 \%$ IDL & Very low \\
\hline Choi et al., 2010 & $\begin{array}{l}\text { Retrospective review of } \\
\text { prospective database }\end{array}$ & $51 / 42$ & 40 Gy (24.2-50.4) & CyberKnife & $\begin{array}{l}\text { Median marginal dose } 20 \\
\text { Gy/2 frx (range } 18 / 1-25 / 5 \text { ) }\end{array}$ & Very low \\
\hline Garg et al., 2011 & Prospective Phase I/II & $63 / 59$ & 33 Gy (30-45) & IG-IMRT & $\begin{array}{l}30 \text { Gy/5 frx (8); } 27 \text { Gy/3 frx } \\
\text { (50); } 20 \text { Gy/5 frx (1) }\end{array}$ & Low \\
\hline Damast et al., 2011 & Retrospective & $92 / 92$ & 30 Gy (8-66) & IG-IMRT & $\begin{array}{l}42 \text { targets: } 20 \mathrm{~Gy} / 5 \mathrm{frx} ; 55 \\
\text { targets: } 30 \mathrm{~Gy} / 5 \mathrm{frx}\end{array}$ & Very low \\
\hline $\begin{array}{l}\text { Mahadevan et al., } \\
2011\end{array}$ & Retrospective & $81 / 60$ & 30 Gy $(8-46)$ & CyberKnife & $25-30$ Gy/5 frx \& 24 Gy/3 frx & Very low \\
\hline Ahmed et al., 2012 & Prospective & $\begin{array}{l}85 / 66 ; 22 \text { were } \\
\text { retreated }\end{array}$ & 30 Gy (8-50.4) & IG-IMRT & $24 \mathrm{~Gy} / 3 \mathrm{frx}$ & Low \\
\hline Chang et al., 2012 & Retrospective & $\begin{array}{c}\text { 180/142; } 54 \text { had } \\
\text { previous RT }\end{array}$ & $39 \mathrm{~Gy} \mathrm{~Gy}_{2}{ }^{*}$ & CyberKnife & $20.6 \mathrm{~Gy} / 1 \mathrm{frx}(18.2-23.7)$ & Very low \\
\hline Thibault et al., 2014 & $\begin{array}{l}\text { Retrospective review of } \\
\text { prospective database }\end{array}$ & $\begin{array}{c}\text { 71/37; } 11 \text { had previ- } \\
\text { ous RT }\end{array}$ & $30 \mathrm{~Gy}$ & IG-IMRT & $24 \mathrm{~Gy} / 2 \mathrm{frx}$ & Low \\
\hline $\begin{array}{l}\text { Thibault et al., } \\
2015^{22}\end{array}$ & $\begin{array}{l}\text { Retrospective review of } \\
\text { prospective database }\end{array}$ & $56 / 40$ & $24 \mathrm{~Gy} / 2 \mathrm{frx}$ & IG-IMRT & $30 \mathrm{~Gy} / 4 \mathrm{frx}$ & Low \\
\hline
\end{tabular}

frx = fraction; GRADE = Grading of Recommendations Assessment, Development and Evaluation; IDL = isodose line; IG-IMRT = image-guided intensity-modulated radiation therapy; $\mathrm{RT}=$ radiation therapy.

${ }^{*} \mathrm{~Gy} \mathrm{y}_{2}$ is a way to normalize radiation doses that may have been given in different dose/fractionation schemes. It converts all doses to the equivalent dose in $2 \mathrm{~Gy}$ per day fractions.

dose limits have been reported specific to both single- and multifraction SBRT, and recommended as a benchmark for safe practice. ${ }^{20}$ It is recognized that the evidence is limited. These suggestions for practice represent expert interpretation of the literature and understanding of clinical practice.

\section{Discussion}

The management of vertebral metastases previously irradiated with cEBRT is a major therapeutic challenge. The fear of causing structural instability and injury to the intimately associated spinal cord has led many to retreat with

TABLE 4. Spine SBRT reirradiation systematic review: treatment outcomes

\begin{tabular}{|c|c|c|c|c|c|c|c|}
\hline Authors \& Year & $\begin{array}{l}\text { Median FU in } \\
\text { Mos (range) }\end{array}$ & FU Schedule & $\begin{array}{l}\text { Definition of } \\
\text { Progression }\end{array}$ & $\begin{array}{l}\text { Local } \\
\text { Control }\end{array}$ & $\begin{array}{l}\text { Overall } \\
\text { Survival }\end{array}$ & $\begin{array}{c}\text { Symptom } \\
\text { Assessment } \\
\text { Scale }\end{array}$ & $\begin{array}{c}\text { Pain } \\
\text { Response }\end{array}$ \\
\hline Sahgal et al., 2009 & $7(1-48)$ & Not defined & $\begin{array}{c}\text { Radiographic or } \\
\text { neurological }\end{array}$ & $1 \mathrm{yr}, 82 \%$ & Median 21 mos & NR & NR \\
\hline Choi et al., 2010 & $7(4-27)$ & MRI every 2-3 mos & Radiographic & $1 \mathrm{yr}, 73 \%$ & $1 \mathrm{yr}, 68 \%$ & NR & $\begin{array}{l}65 \% \text { improve- } \\
\text { ment in pain }\end{array}$ \\
\hline Garg et al., 2011 & $17.6(0.9-67.5)$ & MRI every 3 mos & Radiographic & $1 \mathrm{yr}, 76 \%$ & $\begin{array}{l}\text { Median } 22.5 \\
\text { mos; } 1 \text { yr, } 76 \%\end{array}$ & BPI & $\begin{array}{l}\text { Improvement in } \\
\text { pain at } 6 \text { mos }\end{array}$ \\
\hline Damast et al., 2011 & $12.1(0.2-63.6)$ & MRI every 3-4 mos & Radiographic & 1 yr all, $66 \%$ & Median 13.6 mos & NR & $\begin{array}{l}77 \% \text { improve- } \\
\text { ment in pain }\end{array}$ \\
\hline $\begin{array}{l}\text { Mahadevan et al., } \\
2011\end{array}$ & $12(4-36)$ & $\begin{array}{l}\text { CT } 1 \text { mo post, other- } \\
\text { wise not defined }\end{array}$ & $\begin{array}{c}\text { Radiographic or } \\
\text { neurological }\end{array}$ & $1 \mathrm{yr}, 90 \%$ & Median 11 mos & NR & $\begin{array}{l}79 \% \text { improve- } \\
\text { ment in pain }\end{array}$ \\
\hline Ahmed et al., 2012 & 8.2 & $\begin{array}{l}\text { MRI at } 2 \text { mos \& then } \\
\text { every } 6 \text { mos } \pm \text { PET }\end{array}$ & Radiographic & $1 \mathrm{yr}, 83 \%$ & $1 \mathrm{yr}, 28 \%$ & FACT-G & NR \\
\hline Chang et al., 2012 & 17.3 & $\begin{array}{l}\text { MRI/PET at } 3,6, \& \\
12 \text { mos }\end{array}$ & Radiographic & $1 \mathrm{yr}, 81 \%$ & Median 11 mos & NR & $\begin{array}{l}80.8 \% \text { control } \\
\text { rate at } 1 \mathrm{yr}\end{array}$ \\
\hline Thibault et al., 2014 & $12.3(1.2-55.4)$ & MRI every 2-3 mos & Radiographic & $1 \mathrm{yr}, 73 \%$ & NR & NR & NR \\
\hline Thibault et al., $2015^{22}$ & $6.8(0.9-39)$ & NR & Radiographic & $1 \mathrm{yr}, 81 \%$ & Median 10.0 mos & NR & NR \\
\hline
\end{tabular}

FACT-G = Functional Assessment of Cancer Therapy-General; FU = follow-up; NR = not reported. 
TABLE 5. Spine SBRT reirradiation systematic review: adverse events

\begin{tabular}{|c|c|c|c|c|}
\hline Authors \& Year & Toxicity Scale & $\begin{array}{c}\text { No. } \\
\text { of } \\
\text { VCFs }\end{array}$ & $\begin{array}{c}\text { No. of } \\
\text { Neurological } \\
\text { Adverse } \\
\text { Events }\end{array}$ & $\begin{array}{l}\text { Grade } \\
\text { III-IV } \\
\text { Toxicity, } \\
\text { Other }\end{array}$ \\
\hline $\begin{array}{l}\text { Sahgal et al., } \\
2009\end{array}$ & NCI-CTCAE v3.0 & NR & 0 & 0 \\
\hline Choi et al., 2010 & NR & NR & 1 & 0 \\
\hline $\begin{array}{l}\text { Garg et al., } \\
2011\end{array}$ & $\begin{array}{l}\text { NCl-CTCAE v2.0, } \\
\text { McCormick scale }\end{array}$ & NR & 2 & 0 \\
\hline $\begin{array}{l}\text { Damast et al., } \\
2011\end{array}$ & NR & 9 & 0 & 0 \\
\hline $\begin{array}{l}\text { Mahadevan et } \\
\text { al., } 2011\end{array}$ & NR & NR & 4 & 0 \\
\hline $\begin{array}{l}\text { Ahmed et al., } \\
2012\end{array}$ & NCl-CTCAE v3.0 & 1 & 1 & 0 \\
\hline $\begin{array}{l}\text { Chang et al., } \\
2012\end{array}$ & NCl-CTCAE v2.0 & 12 & 0 & 0 \\
\hline $\begin{array}{l}\text { Thibault et al., } \\
2014\end{array}$ & NR & NR & NR & 0 \\
\hline $\begin{array}{l}\text { Thibault et al., } \\
2015^{22}\end{array}$ & NR & 0 & 0 & 0 \\
\hline
\end{tabular}

$\mathrm{NCl}-\mathrm{CTCAE}=$ National Cancer Institute Common Terminology Criteria for Adverse Events.

an even lower dose of cEBRT than previously delivered. This approach has been proven in a randomized trial to have limited therapeutic impact, with a 2-month overall response rate of $45 \%-51 \%$ and a CR rate of only $11 \%-14 \% .^{6}$

One barrier to the use of retreatment SBRT may be the perceived notion of the poor prognosis for this patient population. However, the median survival for patients following retreatment SBRT ranged from 10 to 22.5 months based on our systematic review. This highlights the need for aggressive therapeutic strategies that are specific to this patient population to optimize local control and symptomatic relief. Spine SBRT was, in fact, developed specifically for reirradiation, with local control rates $>75 \%$ and demonstrable improvements in pain observed in this systematic review. Therefore, we conclude that retreatment SBRT has been shown to be an effective and durable therapy.

Another perceived barrier to the adoption of SBRT to reirradiate spinal metastases was an expected excessive rate of adverse events. However, we observed a modest toxicity profile. The most significant adverse effect remains VCF, as observed in the de novo indication. Our review concludes a crude vertebral fracture rate of $12 \%$ (in keeping with pooled multi-institutional data). ${ }^{18}$ Strategies to mitigate this risk are still in development; factors such as significant lytic disease, baseline fracture, treatment with $>19$ Gy per fraction, and/or a high baseline spinal instability neoplastic score are risk factors warranting a multidisciplinary case discussion with a spinal surgeon. ${ }^{18}$

With respect to radiation myelopathy, which is considered the most feared complication within the discipline of radiation oncology, we observed a low-risk toxicity profile. The crude risk was $1.2 \%$. As experience with reirra-
TABLE 6. ISRS recommendations

\begin{tabular}{lc}
\hline \multicolumn{1}{c}{ Recommendation } & $\begin{array}{c}\text { Level of } \\
\text { Evidence }\end{array}$ \\
\hline $\begin{array}{l}\text { Following cEBRT, retreatment w/ SBRT is a recom- } \\
\text { mended therapeutic option in suitable patients based } \\
\text { on multidisciplinary assessment }\end{array}$ & III \\
\hline Following SBRT, retreatment w/ SBRT is a treatment \\
option in suitable patients based on multidisciplinary \\
assessment
\end{tabular}

diation SBRT has increased globally, guidelines have been published as a benchmark for safe practice to mitigate the risk..$^{19,20}$ This adverse event is no longer considered a barrier to spine SBRT.

Patterns of failure analysis, which were specified in 3 of the 9 series, confirmed epidural progression as the most common site of failure, with 2 other series demonstrating treatment failure as more common in patients with disease in proximity to critical neural structures. This is similar to that observed in the de novo data for spine SBRT., ${ }^{4,9,17}$ Careful delineation of the spinal cord and treating to the maximal spinal cord dose limit $^{24}$ are strategies to reduce the risk of failure.

In addition, because it has been shown that downgrading epidural disease from high grade to low grade can improve outcomes following SBRT, surgical consideration with less invasive approaches is recommended for highgrade epidural disease, even if asymptomatic. ${ }^{13}$ Strategies such as intraoperative brachytherapy to maximize dose within the epidural region while shielding the spinal cord have been reported; however, this remains a new and highly specialized technique with limited application. ${ }^{8}$

Retreatment with a second course of SBRT for SBRT failures, although more fractionated to exploit the capacity for normal tissue repair between fractions, has been prospectively reported to be safe and effective..$^{22}$ Thibault et al. reported on 56 spinal segments, 24 of which had also undergone prior cEBRT followed by SBRT. Even in this heavily pretreated patient cohort, no radiation-induced VCFs or myelopathy cases were identified. Local control rates were encouraging, with a 12-month local control rate of $80.6 \%$. This is an area of active investigation because there will be increasing need to develop the evidence specific to SBRT failures.

Our recommendations are based on 9 publications, only 1 of which was a prospective, single-institution Phase I/II study. Although the level of evidence is low to very low, the outcomes were consistent with respect to durable local control and high rates of pain control. Several limitations are noted in this analysis. Only 9 reports of the 160 that were initially deemed eligible were in fact suitable for final analysis, with significant heterogeneity in patient, treatment, and tumor characteristics.

With respect to outcomes, differences in the definition 
of local control and stringency of posttreatment assessments confound definitive conclusions with respect to local control. Furthermore, an experienced neuroradiologist is imperative to assess whether changes seen on imaging are related to disease progression versus radiation-induced change, because osseous pseudoprogression has been reported and is an active area of investigation. ${ }^{2}$

Similarly, for pain control, the lack of standardization in the pain assessment tool and time points at which response was determined are confounding factors. The SPIne response assessment in Neuro-Oncology (SPINO) group was formed to address such issues. Recommendations have been reported as a first step to standardizing radiation planning, imaging follow-up practices, and response assessment for pain control and local control. ${ }^{23}$ However, despite these limitations, there is consistency with respect to the outcomes reported in our review of the literature. Therefore, we can conclude that reirradiation SBRT is a treatment option that can yield local control and pain control rates superior to cEBRT, and should be considered in selected patients based on multidisciplinary case discussion.

\section{Conclusions}

This systematic review was designed to answer 2 specific clinical questions regarding the management of previously irradiated vertebral body metastases based on best clinical evidence: 1) Is retreatment spine SBRT efficacious with respect to local control and symptom control? 2) Is retreatment spine SBRT safe?

Because spine SBRT is demonstrated to provide symptomatic relief of pain and to confer a local control benefit, the current recommendation is for spine SBRT to be strongly considered as a treatment option, especially in comparison with conventionally fractionated reirradiation treatment.

\section{References}

1. Ahmed KA, Stauder MC, Miller RC, Bauer HJ, Rose PS, Olivier KR, et al: Stereotactic body radiation therapy in spinal metastases. Int J Radiat Oncol Biol Phys 82:e803-e809, 2012

2. Amini B, Beaman CB, Madewell JE, Allen PK, Rhines LD, Tatsui CE, et al: Osseous pseudoprogression in vertebral bodies treated with stereotactic radiosurgery: a secondary analysis of prospective Phase I/II clinical trials. AJNR Am J Neuroradiol 37:387-392, 2016

3. Chang UK, Cho WI, Kim MS, Cho CK, Lee DH, Rhee CH: Local tumor control after retreatment of spinal metastasis using stereotactic body radiotherapy; comparison with initial treatment group. Acta Oncol 51:589-595, 2012

4. Choi CY, Adler JR, Gibbs IC, Chang SD, Jackson PS, Minn AY, et al: Stereotactic radiosurgery for treatment of spinal metastases recurring in close proximity to previously irradiated spinal cord. Int J Radiat Oncol Biol Phys 78:499-506, 2010

5. Chow E, Harris K, Fan G, Tsao M, Sze WM: Palliative radiotherapy trials for bone metastases: a systematic review. J Clin Oncol 25:1423-1436, 2007

6. Chow E, van der Linden YM, Roos D, Hartsell WF, Hoskin $\mathrm{P}, \mathrm{Wu} J \mathrm{~S}$, et al: Single versus multiple fractions of repeat radiation for painful bone metastases: a randomised, controlled, non-inferiority trial. Lancet Oncol 15:164-171, 2014
7. Damast S, Wright J, Bilsky M, Hsu M, Zhang Z, Lovelock M, et al: Impact of dose on local failure rates after image-guided reirradiation of recurrent paraspinal metastases. Int J Radiat Oncol Biol Phys 81:819-826, 2011

8. Folkert MR, Bilsky MH, Cohen GN, Zaider M, Lis E, Krol $\mathrm{G}$, et al: Intraoperative and percutaneous iridium-192 highdose-rate brachytherapy for previously irradiated lesions of the spine. Brachytherapy 12:449-456, 2013

9. Garg AK, Wang XS, Shiu AS, Allen P, Yang J, McAleer MF, et al: Prospective evaluation of spinal reirradiation by using stereotactic body radiation therapy: The University of Texas MD Anderson Cancer Center experience. Cancer 117:3509_ 3516, 2011

10. Gerszten PC, Mendel E, Yamada Y: Radiotherapy and radiosurgery for metastatic spine disease: what are the options, indications, and outcomes? Spine (Phila Pa 1976) 34 (22 Suppl):S78-S92, 2009

11. Hamilton AJ, Lulu BA, Fosmire H, Stea B, Cassady JR: Preliminary clinical experience with linear accelerator-based spinal stereotactic radiosurgery. Neurosurgery 36:311-319, 1995

12. Huisman M, van den Bosch MA, Wijlemans JW, van Vulpen M, van der Linden YM, Verkooijen HM: Effectiveness of reirradiation for painful bone metastases: a systematic review and meta-analysis. Int J Radiat Oncol Biol Phys 84:8-14, 2012

13. Laufer I, Iorgulescu JB, Chapman T, Lis E, Shi W, Zhang Z, et al: Local disease control for spinal metastases following "separation surgery" and adjuvant hypofractionated or highdose single-fraction stereotactic radiosurgery: outcome analysis in 186 patients. J Neurosurg Spine 18:207-214, 2013

14. Mahadevan A, Floyd S, Wong E, Jeyapalan S, Groff M, Kasper E: Stereotactic body radiotherapy reirradiation for recurrent epidural spinal metastases. Int J Radiat Oncol Biol Phys 81:1500-1505, 2011

15. Milker-Zabel S, Zabel A, Thilmann C, Schlegel W, Wannenmacher M, Debus J: Clinical results of retreatment of vertebral bone metastases by stereotactic conformal radiotherapy and intensity-modulated radiotherapy. Int J Radiat Oncol Biol Phys 55:162-167, 2003

16. Rades D, Stalpers LJ, Veninga T, Schulte R, Hoskin PJ, Alberti W: [Effectiveness and toxicity of reirradiation (Re-RT) for metastatic spinal cord compression (MSCC).] Strahlenther Onkol 181:595-600, 2005 (Ger)

17. Sahgal A, Ames C, Chou D, Ma L, Huang K, Xu W, et al: Stereotactic body radiotherapy is effective salvage therapy for patients with prior radiation of spinal metastases. Int J Radiat Oncol Biol Phys 74:723-731, 2009

18. Sahgal A, Atenafu EG, Chao S, Al-Omair A, Boehling N, Balagamwala EH, et al: Vertebral compression fracture after spine stereotactic body radiotherapy: a multi-institutional analysis with a focus on radiation dose and the spinal instability neoplastic score. J Clin Oncol 31:3426-3431, 2013

19. Sahgal A, Ma L, Weinberg V, Gibbs IC, Chao S, Chang UK, et al: Reirradiation human spinal cord tolerance for stereotactic body radiotherapy. Int J Radiat Oncol Biol Phys 82:107-116, 2012

20. Sahgal A, Weinberg V, Ma L, Chang E, Chao S, Muacevic A, et al: Probabilities of radiation myelopathy specific to stereotactic body radiation therapy to guide safe practice. Int $\mathbf{J}$ Radiat Oncol Biol Phys 85:341-347, 2013

21. Thibault I, Al-Omair A, Masucci GL, Masson-Côté L, Lochray F, Korol R, et al: Spine stereotactic body radiotherapy for renal cell cancer spinal metastases: analysis of outcomes and risk of vertebral compression fracture. J Neurosurg Spine 21:711-718, 2014

22. Thibault I, Campbell M, Tseng CL, Atenafu EG, Letourneau D, Yu E, et al: Salvage stereotactic body radiotherapy (SBRT) following in-field failure of initial SBRT for spinal metastases. Int J Radiat Oncol Biol Phys 93:353-360, 2015 
23. Thibault I, Chang EL, Sheehan J, Ahluwalia MS, Guckenberger M, Sohn MJ, et al: Response assessment after stereotactic body radiotherapy for spinal metastasis: a report from the SPIne response assessment in Neuro-Oncology (SPINO) group. Lancet Oncol 16:e595-e603, 2015

24. Tseng CL, Sussman MS, Atenafu EG, Letourneau D, Ma L, Soliman H, et al: Magnetic resonance imaging assessment of spinal cord and cauda equina motion in supine patients with spinal metastases planned for spine stereotactic body radiation therapy. Int J Radiat Oncol Biol Phys 91:995-1002, 2015

25. Wang XS, Rhines LD, Shiu AS, Yang JN, Selek U, Gning I, et al: Stereotactic body radiation therapy for management of spinal metastases in patients without spinal cord compression: a phase 1-2 trial. Lancet Oncol 13:395-402, 2012

\section{Disclaimer}

These guidelines should not be considered inclusive of all methods of care or exclusive of other methods or care reasonably directed to obtain similar results. Physicians must make the ultimate judgment on the basis of the characteristics and circumstances of each individual patient. Adherence to this guideline will not ensure successful treatment in every situation. The authors of these guidelines and the International Stereotactic Radiosurgery Society assume no liability for the information, conclusions, or recommendations contained in this report.

\section{Disclosures}

Mr. Paddick is a consultant for Elekta Instruments. Dr. Sahgal is a consultant for Varian Medical Systems and Hoffmann-La Roche Limited; has received reimbursement for travel accommodations/ expenses and honoraria for previous educational seminars from Elekta, Varian Medical Systems, and Medtronic Kyphoplasty division; and has received research grants from Elekta. Dr. Ma has active patents with the Regents of University of California. Dr. Slotman has received honoraria, travel support, and research grants from Varian Medical Systems and ViewRay (not related to this work). Dr. Myrehaug has received travel support from Novartis and honoraria from Pfizer (not related to this work). Dr. Régis has received consultancy honoraria from Medtronic and Elekta.

\section{Author Contributions}

Conception and design: Sahgal, Hayashi, Levivier, Ma, MartinezAlvarez, Paddick, Régis, Ryu, Slotman, De Salles. Analysis and interpretation of data: Myrehaug, Sahgal. Drafting the article: Myrehaug, De Salles. Critically revising the article: Sahgal, Paddick, Ryu, Slotman, De Salles. Reviewed submitted version of manuscript: all authors. Approved the final version of the manuscript on behalf of all authors: Myrehaug.

\section{Correspondence}

Sten Myrehaug, University of Toronto, Odette Cancer Centre, Sunnybrook Health Sciences Centre, 2075 Bayview Ave., Toronto, ON M4N 3M5, Canada. email: sten.myrehaug@sunnybrook.ca. 